\title{
Legal framework for palliative care the Brazil Unified Health System
}

Keywords: palliative care, patient care, framework, controversies, complexity

\section{Review article}

This article presents a reflection on the jurisprudence related to patient care in palliative care. The theme was criminalized in the Brazilian Constitution of 1988 and in 2002 the first legal framework on the subject was published, but approval only occurred in 2007, after a long legal battle and extensive discussion involving the Federal Public Ministry, civil society and Federal Council of Medicine. It can be affirmed that Brazilian legislation provides legal certainty for the practice of medicine, for the practice of the best care provided to the patient in palliative care, in the terminal phase of life. Given the complexity and controversies of the palliative care issue in Brazil, it is justified to analyze, from the legal perspective, the legal frameworks that define individual rights, limits, state responsibilities and individual protection of legislation. According to Silva et al., ${ }^{1}$ there is a need to increase the knowledge of the proposal for palliative care, in view of the observation of differences in the therapeutic management of the care team and lack of interaction and communication among professionals. This is why it is necessary to elaborate a national policy to promote the care of the terminally ill patient, as well as the permanent training of professionals and the creation of care protocols that promote the comfort of patients and their families during the final phase of life.

In this context, conceptual clarity about the death conditions of the terminal patient is necessary. In Brazil, euthanasia or its counseling, even if for reasons of social, moral or violent value, regardless of the extreme suffering of the patient, is considered a crime in accordance with Article 121 of the Brazilian Penal Code. ${ }^{2}$ Dysthanasia is the exaggerated artificial prolongation of death, which is not intended to prolong life, but the process of death, prolonging the suffering of the person. ${ }^{3}$ Orthotanasia, on the other hand, corresponds to the natural process of death, and the physician's role is to respect the natural course of finitude of life. Thus, in the face of extreme suffering, it is incumbent upon the physician to ameliorate suffering, even if the consequence is indirectly the death of the patient. ${ }^{4}$

There is an understanding regarding the Brazilian Penal Code ${ }^{2}$ that the conduct of the medical professional who does not exhaust all the possibilities of treatment to his patient for the purpose of safeguarding his life commits the crime of homicide in the omissive modality, since it would have the legal duty to carry out treatment to prolong life but did not do so, however, this interpretation does not seem adequate in the face of constitutional principles regarding palliative care. In this sense, behaviors adopted by pediatricians who treat patients with terminal illnesses, mainly reflect the concern to protect themselves against possible judicial processes resulting from the accusation of omission of distress, as well as complex moral conflicts. ${ }^{5}$ Palliative care finds its raison of being and essential justification in Article $1^{\circ}$ of the Constitution of the Federative Republic of Brazil of $1988,{ }^{6}$ which establishes the dignity of the human person as a foundation of the Brazilian State itself. The goal of palliative care is undeniably to
Volume 2 Issue 3 - 2018

\author{
Jackeline Faria Meira,' Kamila Pompermaier \\ Pessimilio,' Leandro Odone Bertelli,' Janine \\ Pereira da Silva, ${ }^{2}$ Valmin Ramos-Silva ${ }^{2}$ \\ 'Medical Residency Program in Pediatrics, Hospital Infantil \\ Nossa Senhora da Glória, Brazil \\ ${ }^{2}$ Master in Public Policy and Local Development, EMESCAM, \\ Brazil
}

Correspondence: Valmin Ramos da Silva, Master in Public Policy and Local Development, EMESCAM,Avenida Nossa Senhora da Penha, 2190, Santa Luiza-Vitória-ES, CEP 29045-402, Brazil, Tel +55-27-33343543,

EmailValmin.Ramos@emescam.br,Valmin.silva@gmail.com

Received: May 29, 2018 | Published: June 20, 2018

guarantee a minimum of dignity for terminally ill patients, avoiding the adoption of treatments that only protect the suffering of patients and their families, thus expressing legal support for palliative care practices. The bases of orthothanasia are based on Article 5 of the Brazilian Constitution $^{6}$ when declaring as a fundamental human right not to be subjected to degrading or inhuman treatment. This is exactly the foundation of the palliative care procedure of terminally ill patients, who have the right to decide independently whether to undergo medical procedures that are not for the purpose of healing but only to delay death.

The first norm of the Brazilian legal system that launched the palliative care in the Brazilian legal system was Portaria $n^{\circ} 19,{ }^{7}$ dated January 3, 2002, which established, under the Unified Health System, the National Pain and Palliative care. In this normative document, the Ministry of Health expressly stated the objective of fomenting the discussion on the subject, as well as establishing, in general terms, what should be understood as palliative care, and indicated the proposals of this program. This instrument that inaugurated the legal framework of palliative care in the Unified Health System established, within the scope of the Health Care Secretariat, the Technical Advisory Group of the National Program of Assistance to Pain and Palliative Care.

The general objectives of the National Program for Pain Relief and Palliative Care are:

i. To articulate governmental and non-governmental initiatives aimed at the care/assistance to patients with pain and palliative care;

ii. To stimulate the organization of health services and multidisciplinary teams for the care of patients with pain and in need of palliative care, in order to establish assistance networks that order this assistance in a decentralized, hierarchical and regionalized manner;

iii. Articulate / promote initiatives aimed at increasing the care culture of pain, the continuing education of health professionals and community education for pain relief and palliative care; 
iv. To develop efforts to organize the collection and dissemination of information relevant to health professionals, patients, families and the population in general, concerning, inter alia, the epidemiological reality of pain in the country, care resources, palliative care, research, new methods of diagnosis and treatment, technological advances, technical and ethical aspects;

v. Develop national guidelines, duly adapted to the Brazilian reality, in order to offer adequate care to patients with pain and/or symptoms related to diseases that are out of reach and in accordance with the international guidelines recommended by the health authorities and societies involved with matter.

The Technical Advisory Group of the National Program for Pain Relief and Palliative Care are:

i. To advise the Ministry of Health and, in particular, the Secretariat of Health Care in the implementation of the Program established by this Order;

ii. Study/evaluate/issue opinions related to pain care and palliative care;

iii. To propose care alternatives and measures necessary to improve pain care/palliative care under the Unified Health System;

iv. To propose public forums on the subject;

v. To advise / advise federal, state, municipal, public or private organs or entities in the organization of services and initiatives aimed at the development of care policies for pain and palliative care.

The institution of the palliative care program is in line with the basic principles of the Unified Health System established by Law $8.080 / 1990,{ }^{8}$ in particular the principle of integrality, which provides for the need to consider the entire patient and in all cases levels of the health care network, as well as with the National Humanization Policy, ${ }^{9}$ instituted in 2003, which provides a humane and dignified treatment to patients, observing and considering their wants and needs. The Brazilian legislation is based on the organization of a health system that integrally absorbs the patients and relatives of patients with advanced and terminal disease. And this will only be possible if this system is based on principles that include care, nonabandonment and protection. The proposal of integrality of the system means the complete assistance to the patient at all levels of the care network giving the patient and his / her relatives the certainty of the reception, being this integrality an important objective of the Unified Health System in Brazil. ${ }^{10}$

Four years after the establishment of the legal framework, the Federal Medical Council issued Resolution ${ }^{\circ} .1805 / 2006,{ }^{11}$ which regulates orthothasia in Brazil. The delay was due to a lawsuit filed by the Federal Public Prosecutor requesting the annulment of the aforementioned CFM Resolution, which was suspended due to an injunction of the judiciary. However, after a great scientific and social debate, the Judiciary rejected the Public Prosecutor's claim, ${ }^{12}$ declaring the legality of said norm, thus producing all its effects. The new sentence reaffirmed that the Resolution represents the manifestation of a new ethic in the medical sciences, which breaks old taboos and decides to face other problems realistically, focusing on human dignity. Thus the doctor authorized by the patient or his legal guardian may limit or suspend exaggerated and unnecessary treatments that prolong the life of the terminally ill patient of serious and incurable diseases.
The Code of Medical Ethics published by Resolution CFM $1931 / 2009^{13}$ deals, in Article 36, from leaving the doctor to the patient under his care. Paragraph $1^{\circ}$ describes that in the event of facts that, at its discretion, impair the good relationship with the patient or the full professional performance, the physician has the right to resign from the service, provided that previously communicated to the patient or his legal representative, ensuring continuity of care and providing all necessary information to the doctor who succeeds. It goes on to say in paragraph $2^{\circ}$ that, except for a just cause, communicated to the patient or his family members, the doctor will not leave the patient because he or she is suffering from chronic or incurable disease and will continue to assist the patient even for palliative care.

The Code of Medical Ethics ${ }^{13}$ also establishes that in cases of incurable and terminal illness, the physician should offer all palliative care available without undertaking useless or obstinate diagnostic or therapeutic actions, always taking into account the expressed will of the patient or, in its impossibility, that of its legal representative. In this sense, there have been advances in the protection of palliative care not only for having ethically supported the behavior of the physician who performs these procedures, but also for having instituted an ethical duty for these professionals to ensure palliative measures according to the patient's wishes in cases terminals. The Resolution of CFM-1995/12, ${ }^{14}$ defined the anticipated directives of will as the set of wishes, previously and expressly expressed by the patient, about the care and treatments that he or she wants, or not, to receive at the moment when he is incapacitated to express, free and autonomously, their will and these will prevail over any other non-medical opinion, including the wishes of family members.

It further established that the decisions of patients who are unable to communicate, or to freely and independently express their wishes, the physician will take into account their anticipated directives of will. However, the doctor will no longer take into account the anticipated directives of will, if in their analysis, these are in disagreement with the precepts dictated by the Code of Medical Ethics of Brazil. The doctor should record in the medical record the advance directives of will that were directly communicated to them by the patient. If the patient's advance directives are not known, and if there is no designated representative, family members available, or lack of consensus among the patients, the physician will refer to the Bioethics Committee of the institution, if any, or, failing that, to the Medical Ethics Committee of the hospital or to the Regional and Federal Medical Council to base their decision on ethical conflicts when they understand this necessary and convenient measure. In this sense, Brazil shows itself to be behind in the normative development of palliative care in the legal system vis-à-vis several other countries that have already regulated the development of palliative measures in their health systems. The United States of America, since 1990, has regulated orthothasias by approving the "Patient Self-Determination Act". ${ }^{15}$ It can even be said that it was in the United States that the subject of self-determination of the patient was developed in a precursor way, serving as a model and beacon for the other countries to regulate the matter.

Based on the examples that have emerged in the United States and on the basis of the discussion that this theme has provided around the world, European countries have included palliative measures in the discussion on bioethics and human rights of patients, so that orthothasia was also discussed and established in 1997 as a guideline in the Convention on Human Rights and Biomedicine held in the city of Oviedo, Spain, in which an agreement was developed between 
countries to establish a convention for the protection of human rights and dignity in relation to biomedicine, a document that became known as the Oviedo Agreement and establishes the general guidelines for palliative measures. ${ }^{16}$ In addition to those mentioned above, several other countries internalized internally the palliative care in the public health of their countries like Italy, Argentina and Uruguay. However, for the purposes of comparative study, the advance brought by Portugal (whose legal traditions are quite close to the Brazilian ones) in relation to orthotania deserves to be highlighted. Already in 2008, with the edition of the Medical Deontological Code, the Portuguese legislation predicted (Article 46) the need for the physician to respect the patient's self-determination. However, it was in 2012, with the edition of Law no. $25 / 2012,{ }^{17}$ that the Portuguese legislation had its main advance in relation to the topic of orthothasia, when elaborating a normative device that deals exclusively with anticipated directives of will and palliative care. Particularly noteworthy in this legislation is the creation of the database of advance directives, in which all the people's directives are stored for consultation by the physician in future clinical cases. Thus, in substitution for the family or even the difficult manifestation of the patient, the doctor can check if there is any manifestation of the will in the database regarding palliative measures.

\section{Conclusion}

Finally, in view of what has been evaluated in Brazilian legislation, it is possible to affirm that Brazilian legislation provides legal certainty for the practice of medicine, for the practice of the best care provided to the patient in palliative care, in the terminal phase of life.

\section{Acknowledgements}

None.

\section{Conflict of interest}

The author declares no conflict of interest.

\section{References}

1. da Silva CF, Souza DM, Pedreira LC, et al. Perceptions of the multi-professional team on the implementation of palliative care in intensive care units. Cien Saude Colet.2013;18(9):2597-604.
2. Brasil. Decreto-Lei No 2.848, De 7 De Dezembro De 1940. Rio De Janeiro, Brazil: Institui O Código Penal. Diário Oficial Da União; 1940.

3. Diniz MH. O estado atual do biodireito. São Paulo, Brazil: Saraiva; 2001.

4. Vieira TR. Bioética e direito. São Paulo, Brazil: Jurídica Brasileira; 1999.

5. Linhares DG, Siqueira JE, Previdelli ITS. Limitation of life support in the pediatric intensive care unit. Rev bioét. 2013;21(2): 291-297.

6. Brasil. Constituição da República federativa do Brasil. Brasília: Diário Oficial da União em; 1988.

7. Brasil. Portaria do Ministério da Saúde. Brazil: Diário Oficial da República Federativa do Brasil; 2012. 16 p.

8. Brasil. Dispõe sobre as condições para a promoção, proteção e recuperação da saúde, a organização e o funcionamento dos serviços correspondentes e dá outras providências. Brazil: Diário Oficial Da República Federativa Do Brasil; 1990. 18 P.

9. Brasil. Secretaria de assistência à saúde programa nacional de humanização da assistência hospitalar / ministério da saúde, secretaria de assistência à saúde. Brasília: Ministério da Saúde.

10. Floriani Ca, Schramm Fr. Desafios morais e operacionais da inclusão dos cuidados paliativos na rede de atenção básica. Caderno De Saúde Pública. 2007;23(9):2072-2080.

11. Brasil. Resolução do Conselho Federal de Medicina. Brazil: Diário Oficial da República Federativa do Brasil; 2006. 169 p.

12. Brasil. Justiça Federal do Distrito Federal. Brazil: Ação Civil Pública; 2007.

13. Brasil. Resolução do Conselho Federal de Medicina. Brasília: Diário Oficial da República Federativa do Brasil; 2009. 90 p.

14. Brasil. Resolução do Conselho Federal de Medicina. Brasília: Diário Oficial da República Federativa do Brasil; 2012. p. 269-270.

15.http://testamentovital.com.br/legislacao/estados-unidos/

16. Convenção para a Proteção dos Direitos do Homem e da Dignidade do Ser Humano face às aplicações da Biologia e da Medicina. Oviedo, Spain: Conselho Da Europa; 1997.

17.http://www.pgdlisboa.pt/1eis/1ei_mostra_articulado. php?nid=1765\&tabela=leis 